\title{
Impact of a Surface on the Electro-Reflectance Spectra of n-Si(110) and their Polarization Anisotropy
}

\author{
V.E. Lashkaryov Institute of Semiconductor Physics NAS of Ukraine, Kyiv, Ukraine, rastneg@isp.kiev.ua
}

\begin{abstract}
The electro-reflectance spectra, including their polarization dependencies were analyzed for $\mathrm{n}-\mathrm{Si}(110)$ in the energy range of $2.9-3.8 \mathrm{eV}$. Based on the optical anisotropy of electro-optical effect, two contributions originated from a surface, (isotropic part relates to the linear electro-optical effect which inherent for (110) surface) and bulk, (anisotropic part relates to the Franz-Keldysh effect) were identified and separated. The presence of such extreme is explained by the zero value of the electron wave function on the surface and (or) the structure gettering of the free carriers.
\end{abstract}

Keywords: electro-reflectance, Franz-Keldysh effect, surface and bulk contributions of electro-reflectance, n-Si (110).

Received 19 August 2020; Accepted 15 September 2020.

\section{Introduction}

The thickness of skin-layer, forming the electroreflectance signal which inherent for the direct band-toband transitions, is determined by the two characteristic lengths, $L_{D}\left(L_{T F}\right)$, and $d$. Former is the Debye, $L_{D}=\left(\varepsilon \varepsilon_{0} k T / e^{2} n\right)^{1 / 2}, \quad$ or $\quad$ Thomas-Fermi, $L_{T F}=\left(\varepsilon \varepsilon_{0} k T F_{1 / 2}\left(\mu^{*}\right) / e^{2} n F_{-1 / 2}\left(\mu^{*}\right)\right)^{1 / 2} \quad$ (depending on statistics) screening lengths. It defines the spatial scale of near-surface region where effect of the band bending is important. Latter is the light penetration depth, $d=\lambda / 4 \pi|N|$, where $N=n+i \chi$ is a complex refractive index. All designations in formulas are the conventional and generally accepted. The important experimental techniques of investigations of the physics of surface states is the electrolytic technique [1-3]. One uses an alternative voltage for a modulation of the values of the built-in fields of surface barrier. Additionally, the application of the steady-state bias allows us to vary the average values of the built-in fields. Other optical technique is the modulation spectroscopy of the electroreflectance that allows to identify the energy of the direct optical interband transitions, $E=\hbar \omega$. This technique is based on the measurements of the spectral characteristics of the relative reflection coefficient, $\Delta R / R=\left(R_{F}-R\right) / R \quad$ (signal of electro-reflectance), where $R_{F}$ - reflectivity of the sample subjected to field $F$ which includes both alternative voltage and steadystate bias and $R$-reflectivity of the sample without electric field $F$.

It should be noted that relative reflection coefficient is usually measured in the energy range larger than the fundamental absorption edge, when the light transmission through the sample is the negligibly small, due to the high values of the absorption coefficient, $\alpha$. Mainly this techniques is oriented on the study of the direct interband transitions where intensity of the transition and oscillator force are in two orders larger than for indirect ones. For indirect transitions, the electro-reflectance signal, $\Delta R / R$, takes the values of $10^{-}$ ${ }^{8}$, which are typically beyond the sensitivity threshold of the experimental setups.

Utilization of the modulation spectroscopy of the electro-reflectance gives a possibility of the structural analysis of the sample surfaces, their quality, including the identification of the effect of the chemical and physical processing on the surface state. Moreover, such 
kind spectroscopy can be important for the analysis of as actual semiconductor compounds $[4,5]$ as well the modern quantum heterostructures, including quantum well's and superlattice's heterostructures, where built-in electrostatic fields can reach enormous values of $10^{6}$ $10^{8} \mathrm{~V} / \mathrm{m}$. The separation mechanism of the surface and bulk contributions implies that surface contribution $(\Delta R / R)_{S}$ is the isotropic and bulk contribution $(\Delta R / R)_{V}$ is the anisotropic with respect to a polarization of light. In Refs. [6-9] the mentioned separation mechanism was used for study different physical processes of the formation of near-surface electron states and their interaction with photons. The aim of the present paper is to separate the surface and bulk contributions in electro-reflectance signal and to study the physical phenomena occurring near surface of the ndoped Si sample with orientation of (110).

\section{Result and discussion}

The electro-reflectance spectra of the $\mathrm{n}$-Si(110) single crystal with the electron concentrations of $\mathrm{n}=10^{18}-10^{19} \mathrm{~cm}^{-3}$, were studied in spectral range of $2.8-$ $3.8 \mathrm{eV}$ by means electrolytic technique at the two polarization of light $\hat{e} \|[001]$ and $\hat{e} \|[1 \overline{1} 0]$. The measurements were performed at the room temperature. The high carrier concentrations facilitate the separation between bulk and surface contributions in the electroreflectance signal, as a result, to study the surface impact in details. In the experiments, electro-reflectance spectra of chemically-etched surface exhibit a variation of energetic positions of the characteristic zeros of electroreflectance signal with respect to the variation of polarization of the incident radiation. It proves the violation of the criterion of the small-field regime. However, the absence of the Franz-Keldysh oscillations denotes that the intermediate case is realized when electro-optical energy is the same order of the broadening parameter. It should be noted that in the range of the intermediate electric fields the variation of the dielectric permittivity $\Delta \varepsilon=\varepsilon(E, F)-\varepsilon(E, 0)$ is linear with respect to the electric field $\mathrm{F}$.

Fig. 1 demonstrates the electro-reflectance spectra of $\mathrm{n}$-Si(110) surface (initially chemically-etched $\mathrm{n}$-Si(110) with bulk electron concentration $\mathrm{n}=10^{18}-10^{19} \mathrm{~cm}^{-3}$, measured at the two polarizations of incident light and were obtained at the weak negative bias when Si surface is enriched by the electrons. Using these spectra, the surface $(\Delta R / R)_{S}$ and bulk $(\Delta R / R)_{V}$ contributions can be separated.

The assumption that, surface contribution of electroreflectance signal is an isotropic with respect to the orientation of the polarization vector and bulk contribution is an anisotropic is based on the properties of the surface linear electro-optic effect in the crystals with cubic symmetry [10]. Indeed, let us consider near the surface a transition layer with thickness $d_{S}$ and complex refractive index $N_{S}=n_{S}+i \chi_{S}$ which is distinguished from bulk refractive index,

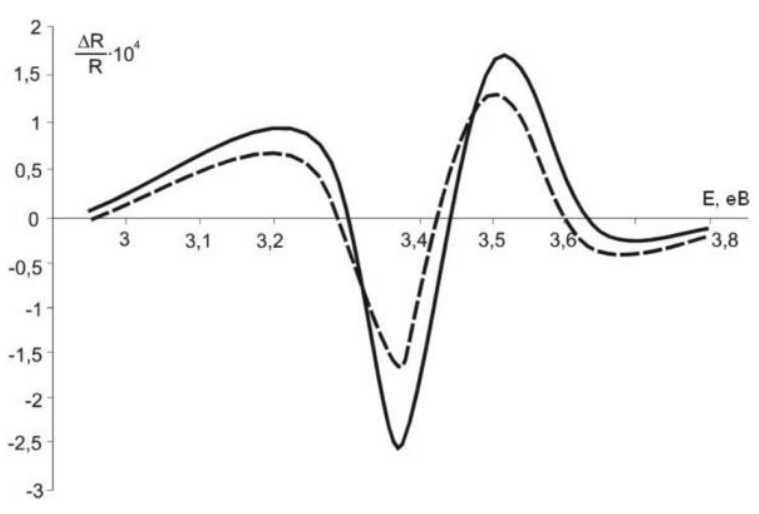

Fig. 1. Measured electro-reflectance spectra of nSi(110) at two polarization: $\hat{e} \|[001]$ (solid line) and $\hat{e} \|[1 \overline{1} 0]$ (dashed line).

$N_{V}=n_{V}+i \chi_{V}$. Under the assumption that the resulting electro-reflectance signal is determined by the variation of the real, $\Delta \varepsilon_{1}$ and imaginary, $\Delta \varepsilon_{2}$ parts of dielectric permittivity, we can write that $\Delta R / R=A \Delta \varepsilon_{1}+B \Delta \varepsilon_{2}$, where $A$ and $B$ are the partial Seraphin coefficients [2]. Then, for $\hat{e} \|[1 \overline{1} 0]$ polarization latter gives:

$$
\frac{\Delta R}{R}=\sum_{i=1}^{2}\left(A_{i} \Delta \varepsilon_{i s}+B_{i} \Delta \varepsilon_{i v}\right)=\left(\frac{\Delta R}{R}\right)_{S}+\left(\frac{\Delta R}{R}\right)_{V},
$$

and for $\hat{e} \|[001]$ polarization:

$S\left(\frac{\Delta R}{R}\right)=\sum_{i=1}^{2}\left(A_{i} \Delta \varepsilon_{i s}+S_{0} B_{i} \Delta \varepsilon_{i v}\right)=\left(\frac{\Delta R}{R}\right)_{S}+S_{0}\left(\frac{\Delta R}{R}\right)_{V}$,

where $S_{0}$ - polarization coefficient of the anisotropic bulk contribution of the electro-optical effect which relates to the Franz-Keldysh effect. Further, we assume that due to the strong screening effect of the surface the criterion of weak electric fields [11] takes place. At this, coefficient $S_{0}$ should be constant over all spectral range and should be same for the both real and imaginary parts of $\Delta \varepsilon_{V}$ [12]. From relationships (1) and (2) we obtain that:

$$
\begin{aligned}
& \left(\frac{\Delta R}{R}\right)_{S}=\frac{S_{0}-S}{S_{0}-1} \frac{\Delta R}{R}, \\
& \left(\frac{\Delta R}{R}\right)_{V}=\frac{S-1}{S_{0}-1} \frac{\Delta R}{R} .
\end{aligned}
$$

The coefficient of polarization anisotropy of the volume component of the electro-optical effect $S_{0}$ is equal to

$$
\mathrm{S}_{0}=\frac{2}{3} \frac{m_{t}+2 m_{l}}{m_{t}+m_{l}}
$$

For silicon $\mathrm{m}_{l}=0.92 \mathrm{~m}_{0} ; \mathrm{m}_{\mathrm{t}}=0.19 \mathrm{~m}_{0}$ [13], this implyies $\mathrm{S}_{0}$ is 1.22 .

When dividing the contributions of the surface component $(\Delta R / R)_{S}$ and the volume component $(\Delta R / R)_{V}$ of the electro-reflectance spectra according to formulas (3) and (4), $S=(\Delta R / R)_{\hat{e} \|[001]}-(\Delta R / R)_{\hat{e} \|[1 \overline{1} 0]}$;

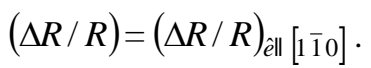


The result of the dividing of contributions $(\Delta R / R)_{S}$ (dashed line) and $(\Delta R / R)_{V}$ (solid line) is shown in Fig. 2. Bulk contribution $(\Delta R / R)_{V}$ is obtained for incident light wave with the polarization $\hat{e} \|[1 \overline{1} 0]$. Amplitude of quantity $(\Delta R / R)_{V}$ obtained for polarization of $\hat{e} \|[001]$ is in $S_{0}$ times larger than in the previous case. From obtained results, we see that the form of the spectrum of bulk contribution (relates to the Franz-Keldysh effect) is well-agreed with measured one at the low levels of the electron enrichment. Also, we plotted in Fig. 3 the difference spectrum $(\Delta R / R)_{\hat{e} \|[001]}-(\Delta R / R)_{\hat{e} \|[1 \overline{1} 0]}$.

The obtained results in Figs. 2 and 3. indicate almost same forms of electro-reflectance spectrum corresponding to the bulk contribution and the difference spectrum. In Ref. [3] it was noted that the surface contribution can be estimated on the basis of differences in anisotropic optical spectra. The difference of optical spectra measured at different vectors of light wave polarization, ie the difference of optical spectra at different vectors of light wave polarization is used in spectroscopy of difference reflectance (electroreflectance) to diagnose semiconductor materials and

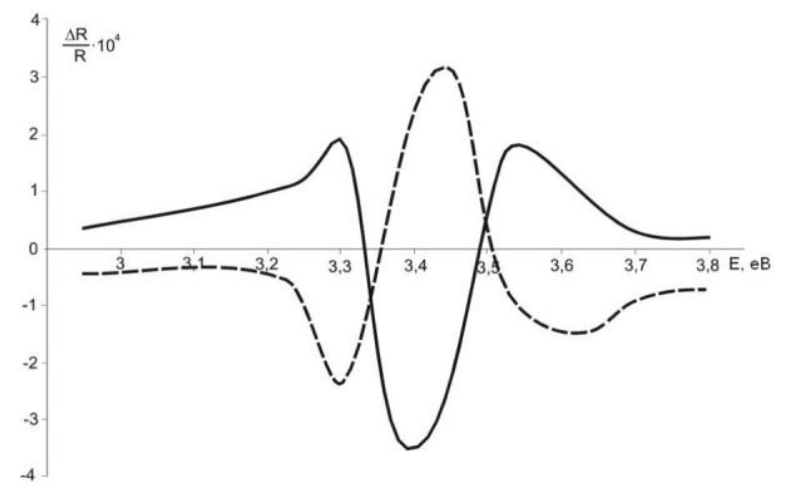

Fig. 2. Bulk contribution of electro-reflectance spectrum (Franz-Keldysh effect) (solid line) and surface contribution of electro-reflectance spectrum (dashed line) obtained by means of polarization dependence of the electro-optical effect.

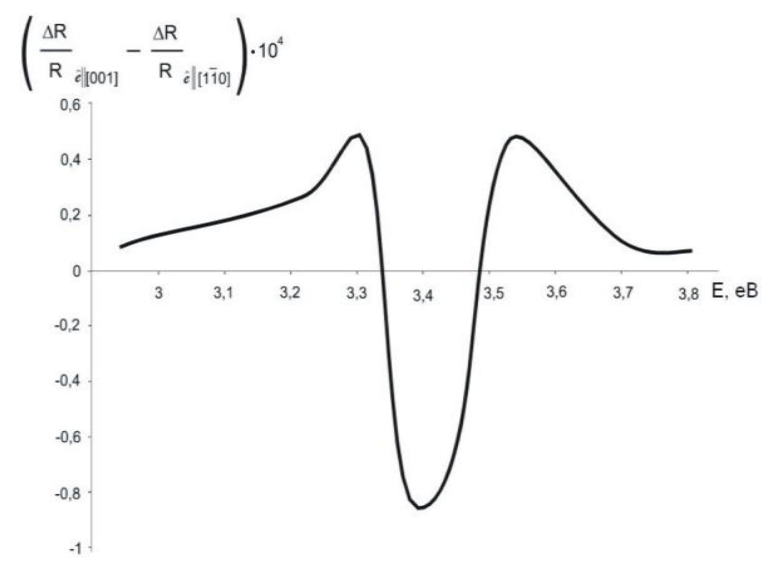

Fig. 3. Difference spectrum of electro-reflectance at two polarization of light $\hat{e} \|[001]$ and $\hat{e} \|[1 \overline{1} 0]$. structures based on them. The same forms of two latter spectra prove the assumptions that were used at separation of the bulk and surface contributions in the electro-reflectance signal.

It should be noted, that dependence of $\varepsilon(E, \hat{e})$ vs polarization $\hat{e}$ is the considarable due to the symmetry of Si surface with orientation (110). The phase difference between surface and bulk contributions is the result of the non-monotonic behavior of the spatial profile of built-in electrostatic potential $V(z)$ near the surface. I.e, energy diagram (schematically sketched in Fig. 4) contains an extremum.

The order of sequence of the extrema in measured electro-reflectance spectra of $\mathrm{n}-\mathrm{Si}(110)$ (Fig.1) indicates that we have the situation of the upward band bending. Since the surface is etched (no surface charges), the emergence of such extrema can be connected with the fact that the electron wave function $\psi(z)$ is equal to zero on the surface. Indeed, we have the situation of enriched surface when the De Broglie wavelength of electrons

$$
\lambda_{D-B}=2 \pi \hbar / \sqrt{2 m_{n}^{*} k T},
$$

which takes part in optical transition is comparable with space-charge region. So, for $\mathrm{Si} m_{n}^{*}=0.92 m_{0}$, $\lambda_{D-B}=8.08 \mathrm{~nm}$.

As a result, the complex refractive index, $N=n+i \chi$, of the near-surface layer is changed (one is responsible for electro-reflectance signal). This index is determined by non-equilibrium electron concentration.

The reason of the emergence of such extremum can be explained by the structural gettering of the surface. Such gettering is the results of the possible existence of the different surface imperfections which can effectively accumulate point defects and can couple the impurities. In $\mathrm{Si}$, the different compounds such as $\mathrm{SiO}_{\mathrm{x}}, \mathrm{SiO}_{2}, \mathrm{Si}_{3} \mathrm{~N}_{4}$, $\mathrm{SiO}_{2-x} \mathrm{P}, \mathrm{SiC}$ can play such role.

From quantitative analysis of the electro-reflectance spectra of $\mathrm{n}$-Si (110) sample with bulk concentration $\mathrm{n}=5 \cdot 10^{18} \mathrm{~cm}^{-3}$, using the phenomenological approach

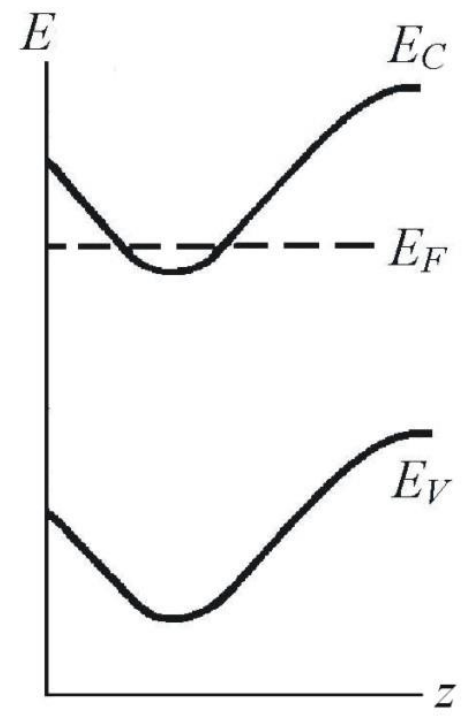

Fig. 4. Sketch of Energy diagram of chemically etched surface of n-Si with orientation (110). 
proposed in Refs. [14-16], we found the following physical parameters, including the parameters of the space-charged region:

$$
\begin{gathered}
E_{1}=\Lambda_{1}^{C}-\Lambda_{3}^{V}=3.38 \mathrm{eV}, \hbar \theta=4.8 \times 10^{-2} \mathrm{eV}, \\
\Gamma=0.1 \mathrm{eV}, \quad F s=7.6 \times 10^{6} \mathrm{~V} / \mathrm{m}, \\
\tau=\hbar / \Gamma=6.58 \times 10^{-15} \mathrm{~s}, \mu=0.02 m_{0}, \\
\lambda_{F K}=\hbar \theta / e F_{S}=6.32 \times 10^{-9} \mathrm{~m} .
\end{gathered}
$$

The light penetration depth in the range of 2.9 $3.8 \mathrm{eV}$ is varied from $7.53 \mathrm{HM}$ (at $E=3.8 \mathrm{eV}$ ) to $9.87 \mathrm{HM}$ (at $E=2.9 \mathrm{eV}$ ). The dielectric permittivity of $\mathrm{Si}$, $\varepsilon=11.9$. The size of the space-charged region can be estimated according to following formula: $L_{D}=\left(\varepsilon \varepsilon_{0} k T / e^{2} n\right)^{1 / 2}$. In our case $L_{D}=1.81 \mathrm{Hм}$. From here it follows that electric field along $\mathrm{z}$ direction is the essentially non-uniform.

\section{Conclusions}

The obtained results can be summarized as follows:

1. The surface and bulk contributions in the electroreflectance signal were separated based on the assumption of the essential polarization anisotropy of the electro-optical effect for the bulk contribution and isotropic electro-optical effect for the surface contribution.
2. The spectrum of the bulk contribution $(\Delta R / R)_{V}$ of electro-reflectance signal with respect to position of the characteristic peaks is agreed with extracted from measurements the spectrum of combination $(\Delta R / R)_{\hat{e} \|[001]}-(\Delta R / R)_{\hat{e} \|[1 \overline{1} 0]}$ in the range of weak enrichment of the $\mathrm{n}-\mathrm{Si}(110)$ surface.

3. The obtained results can be explained by the specific form of the energy diagram with extremum. Latter can be associated with surface gettering by different compounds such as $\mathrm{SiO}_{x}, \mathrm{SiO}_{2}, \mathrm{Si}_{3} \mathrm{~N}_{4}, \mathrm{SiO}_{2-x} \mathrm{P}$, $\mathrm{SiC}$, etc.

4. From the analysis of the electro-reflectance spectra of $\mathrm{n}$-Si(110) sample with concentration of $5 \cdot 10^{18} \mathrm{~cm}^{-3}$, we found the values of the important physical parameters:

$$
\begin{gathered}
E_{1}=\Lambda_{1}^{C}-\Lambda_{3}^{V}=3.38 \mathrm{eV}, \quad \hbar \theta=4.8 \times 10^{-2} \mathrm{eV}, \\
\Gamma=0.1 \mathrm{eV}, \quad F s=7.6 \times 10^{6} \mathrm{~V} / \mathrm{m}, \\
\tau=\hbar / \Gamma=6.58 \times 10^{-15} \mathrm{~s}, \quad \mu=0.02 m_{0}, \\
\lambda_{F K}=\hbar \theta / e F_{s}=6.32 \times 10^{-9} \mathrm{~m} .
\end{gathered}
$$

Gentsar P. - Ph. D., Senior Researcher;

Vuichyk M. - Ph. D., Senior Researcher;

Stronski A. - Doctor Sciences, Head Department of Physics of Optoelectronic Devices.

[1] M. Cardona, Solid State Physics: Modulation Spectroscopy (Academic Press: 1969).

[2] V.A. Tyagay, O.V. Snitko, Electrootrazheniye sveta v poluprovodnikah (Kyiv: Naukova Dumka: 1980) (in Russian).

[3] P. Yu, M. Cardona, Osnovy poluprovodnikov (Fizmatlit, Moskow, 2002) (in Russian).

[4] Yu.V. Borobyev, V.N. Dobrovolski, V.I. Strikha, Metodi isledovaniya poluprovodnikov (Vyscha Shkola, Kyiv, 1988) (in Russian).

[5] G.P. Peka, V.I. Strikha, Poverhnevi ta kontaktni yavyscha v napivprovidnikah (Lybid', Kyiv, 1992).

[6] A.M. Yevstigneev, O.V. Snitko, L.V. Artamonov, P.O. Gentsar, A.N. Krasiko, Ukr. J. Phys. 31(5), 756 (1986).

[7] A.M. Yevstigneev, O.V. Snitko, A.N. Krasiko, P.O. Gentsar, Ye.V. Mozdor, Ukr. J. Phys. 32(2), 269 (1987).

[8] O.I. Vlasenko, P.O. Gentsar, A.V. Stronski, Functional Materials 16(3), 286 (2009).

[9] P.O. Gentsar, New technology: Issue of Kremenchuk University of Economy, Information technology and Management 3(33), 17 (2011) (in Ukrainian).

[10] R.Del Sole, D.E. Aspnes, Phys. Rev. B 17(8), 3310 (1978) (https://doi.org/10.1103/PhysRevB.17.3310).

[11] D.E. Aspnes, Surface Schience 37(2), 418 (1973) (https://doi.org/10.1016/0039-6028(73)90337-3).

[12] K. Kondo, A. Moritani, Phys. Rev. B 14(4), 1577 (1976) (https://doi.org/10.1103/PhysRevB.14.1577).

[13] K.V. Shalimova, Fizika poluprovodnikov (Moskow: Energoatomizdat: 1985) (in Russian).

[14] E.F. Venger, P.O. Gentsar, L.A. Matveeva, Ukr. J. Phys. 51(7), 679 (2006).

[15] P.A. Gentsar, A.I. Vlasenko, Semiconductors 40(9), 1066 (https://doi.org/10.1134/S1063782606090144).

[16] P.O. Gentsar, O.I. Vlasenko, O.V. Stronskii, Physics and Chemistry of Solid State 7(4), 780 (2006). 


\section{П.О. Генцарь, М.В. Вуйчик, О.В. Стронський}

\section{Вплив поверхні на спектри електровідбивання n-Si(110) та їх поляризаційну анізотропію}

Інститут фізики напівпровідників ім. В.С. Лашкарьова НАН Украӥни, Київ, Украӥна, rastneg@isp.kiev.иа

Проаналізовано спектри електровідбивання, включаючи їх поляризаційні залежності, для n-Si (110) в енергетичному діапазоні 2,9 - 3,8 еВ. Були ідентифіковані та відокремлені два внески, що випливають із поверхневої (ізотропна частина відноситься до лінійного електрооптичного ефекту, властивого для (110) поверхні) та об'ємної складових (анізотропна частина стосується ефекту Франца - Келдиша) на основі оптичної анізотропії електрооптичного ефекту. Наявність такої крайності пояснюється нульовим значенням функції електронної хвилі на поверхні та (або) структурним гетеруванням вільних носіїв.

Ключові слова: електровідбивання, ефект Келдиша-Франца, поверхнева складова електровідбивання, об’ємна складова електровідбивання, n-Si (110). 